\title{
Women's transit safety: making connections and defining future directions in research and practice
}

\author{
Vania Ceccato 1
}

(C) Macmillan Publishers Ltd 2017

\begin{abstract}
Drawing from a diverse range of examples, the guest editor aims to summarise and reflect upon the key material presented in this special issue. This 'afterword' to the special issue also highlights the key messages that emerge from the diverse research techniques and methodologies employed in the varied range of case studies, most of them small-scale studies. This final article identifies the unanswered questions and looks forward discussing future research agendas and policy recommendations that arise from this international and multidisciplinary take on women's victimisation and perceived safety in transit environments.
\end{abstract}

Keywords Gender violence · Crime in transit settings · Case studies · International perspective

\section{Introduction}

The right to mobility is intrinsic to women's access to public space. Yet, this right cannot be taken for granted since in many countries women have no other choice than to define different strategies to avoid victimisation and unsafe places. An empty train in the evening might allow the anonymity necessary for an offender to commit a rape (Ceccato et al. 2017; Gekoski et al. 2015; Hewitt and Beauregard 2014). More commonly, it is the crowded buses or trains during rush hours that just might provide the right opportunity for groping and all sorts of inappropriate sexual behaviours (Madan and Nalla 2015; Natarajan 2016). Given that sexual victimisation is never justified, we discuss in this afterword examples from the articles in

Vania Ceccato

vania.ceccato@abe.kth.se

1 Department of Urban Planning and Environment, School of Architecture and the Built Environment (ABE), KTH Royal Institute of Technology, Drottning Kristinas väg 30, 10044 Stockholm, Sweden 
this special issue to characterise women's behaviour (over which women should be free to have total autonomy and carry out in the absence of the threat of sexual victimisation) in situational contexts in which women become targets. This is of relevance since the identification of these conditions is crucial to create opportunities for prevention.

This 'afterword' aims at synthesising the main issues that emerge from the eight different case studies that constitute this special issue. It also identifies remaining questions in the research on women's transit safety as well as future research agendas and general policy recommendations.

The structure of this article is as follows. First the main emergent messages are discussed, followed by limitations, unanswered questions and future research. The article finishes with recommendations and conclusions.

\section{Women's transit safety: main emergent, cross-cutting themes}

Throughout this special issue there are several reoccurring themes, some of which are highlighted here as they represent some of the complexities and challenges present in improving research and practices in women's transit safety.

\section{Sexual crimes against women in transit: an invisible problem}

The message is unanimous across all articles of this special issue: sexual crime against women in transit (cases of staring, touching, groping, ejaculation, exposing genitalia and full rape) is a highly underreported offence (e.g. Datafolha 2014; Gekoski et al. 2015; Madan and Nalla 2015; Natarajan 2016). Low reporting rates have many causes; some of the most known relate to societal norms of behaviour between men and women in public places (Ceccato et al. 2017; Harris et al. 2017; Suarez and Gadalla 2010; Valentine 1990, 1992) but may also be related to "what is there' in terms of infrastructure making it possible for victims to report a crime.

We first consider the issue of societal norms of behaviour in transit and actions of bystanders. The article by Tripathi and colleagues indicate that 'acts of sexual harassment were not widely noticed by other passengers', perhaps because they were 'commonplace' (this finding has been reinforced by other studies in this special issue, see Natarajan and colleagues, Ceccato and Paz, Lea et al.). Findings from Lea et al., article suggest that it is necessary to provide a better sense of assurance to women and girls to draw attention to what is happening, so that, as suggested in Ball and Wesson's article, bystanders have a chance to intervene. Those passengers who are faced with sexual crimes while riding a bus or train (either themselves or as witnesses) may still think that it is not 'acceptable to make a scene' under those circumstances. Thus, if this attitude continues, the problem will remain be invisible.

Now we turn to the issue of available infrastructure making it possible for victims to report a crime while in transit. Several articles in this special issue have mentioned that the perception of a lack of support, both during and after the crime occurs, highly contributes to victims deciding to not to report to the police. If the police are not there, or if 'it is too difficult' to file a report, reported cases of sexual 
crimes against women in transit will continue to be low (see e.g. articles by Natarajan and colleagues and Ceccato and Paz). In the case of the São Paulo metro, the distribution of personnel across the system (including security guards) highly affects the geography of reporting crime against women in transit.

\section{We cannot see the trees for the forest: women as a heterogeneous group}

Two studies in this special issue focus on the profiles of women as users in transit environments and their safety (Vanier and Jubainville, and Iudici and colleagues). What comes out of these two studies is that women as transit users are far from a homogenous group; a finding that has an impact on both research and policy implications, also shown elsewhere (Loukaitou-Sideris 2016). For instance, based on women's individual characteristics and mobility habits, Vanier and Jubainville identify four types of female passengers in relation to their declared perceived safety. This implies that they react differently when facing the same situation. Iudici and colleagues come to similar conclusions, but in the context of transit users' safety and disability. They remind us that disability can be multifaceted, often emerging from the intersectionality of a multitude of individual characteristics. Thus, in order to consider women's needs in transit, it is essential to consider differentiated levels of vulnerabilities, and, in particular, women with disabilities, who are more often an easy target of sex offenders. The intersectionality of women's safety (age, economic status, ethnicity but also differences in physical and cognitive abilities, see e.g. Sokoloff and Dupont 2005) is a reoccurring topic in this special issue, yet it is still a topic not well understood in the context of transit safety.

\section{We cannot see the forest for the trees: women's transit safety requires 'a whole journey approach'}

Managers of public transport systems seeking to maintain or increase ridership need to be aware of the security needs of passengers on their systems, including of women as passengers. The 'whole journey' approach to safety (door-to-door) can be helpful to highlight aspects of the transit journey for women passengers that require special attention among transport providers, local governmental authorities, policy makers and researchers (Smith 2008; Loukaitou-Sideris 2016). In this special issue, safety in transit environments has been translated into safety at particular transport nodes: either the interiors of buses, carriages or stations. This is of course problematic because it reduces 'safety' along the entire trip to a sample of potential risks and/or declared perceived safety at a particular spot. The exception was the paper by Natarajan and colleagues that explicitly attempted to apply a 'whole journey' approach, as an analytical framework, to women's safety. By looking at safety during the whole trip (walking to and from the bus/subway stops as well as waiting for, and riding on the bus or subway), these authors find that women's safety is compromised along the whole trip. In other words, they find extensive patterns of victimisation during all stages of female students' subway commute to and from college. Another advantage of looking at the whole trip is that it allows us to identify the most critical environments (and times) in which women feel at risk- 
valuable information both from the perspective of those who are responsible for the supply side of service delivery and from those who use the system.

\section{Women's transit safety: a question of individuals' rights}

All articles of the special issue point out that environments characterised by high densities of passengers (overcrowding), e.g. in buses, carriages or stations, are commonly a fertile territory for sexual harassment and other types of sexual abuse and harassment (Ceccato and Paz, in this issue). This is a particular, although not exclusive, problem in big cities in countries of the Global South where the poor supply of public transportation means that women are even more exposed to sexual victimisation. Although overcrowding is not considered here to be a cause of sexual crime against women in transit, it is definitely a facilitator. The problem of overcrowded transportation calls for better transportation supply and management that attend passengers' needs for reliable and safe public transportation. This means that the question of women's safety has to be first framed in a wider context, namely that of individuals' needs and right to basic public goods. If this basic need is not satisfied, which is still the case in many transportation systems in cities of the Global South, then radical improvements in women's safety will be difficult to attain in the short term. Transit safety needs to be addressed in terms of joint responsibility with intersectoral action. Although as Sweet and Escalante (2010, p. 2144) indicates 'we still have a long way to go before planning is able to respond to and prevent gender violence in an equitable manner' but changes are on the way. UN Women's Safe Cities and Safe Public Spaces initiatives are continuously generating a number of innovative results through partnerships with local governments, national governments, women's groups and other community partners (UN Women 2017). The article by Lea et al in this issue is also an example of this technological development having women's participation as a key feature.

\section{Women's transit safety: a multidisciplinary field}

Although the articles in this special issue arise from different disciplines, they more often than not share a number of commonalities and theoretical principles. The articles illustrate that the topic of women's transit safety is a rich, multidisciplinary field, which, in practice, has developed from different disciplines and theoretical principles (for example criminology, urban planning, transport planning, sociology, psychology, geography, architecture and security). The increasing volume of available space and time data (for instance, from mobile devices and crowdsourcing) constitutes the new frontier of research, as it demands methods capable of guiding and dealing with different types of data. In practice too, as problems become more complex, a variety of stakeholders are or need to become involved. As reality demands more integrated, holistic and cross-disciplinary research, there is no doubt that this is the way forward. However, as Ekblom (2014) suggested, it is a challenge to communicate a particular problem to appropriate audiences, researchers and experts, including other relevant organisations. Despite these difficulties this special issue illustrates that is possible to spell out different approaches to a single theme, such as women's transit safety. 


\section{Limitations, unanswered questions and future research}

Most articles in this special issue are based on case studies, many of them exploratory studies, based on small-sample datasets. This means that findings cannot be generalised to the entire populations from which they arose. The fact that most articles are qualitative also means that this area remains largely uncharted as researchers are still attempting to gain a more in-depth understanding of the nature of the phenomenon. These studies are based on self-collected or crowdsourced data because secondary sources may not be appropriate to elucidate issues of women's safety in transit or are of poor quality. For instance, national victimisation surveys in most countries (France being an exception) do not include questions of transit safety. Even if they do, the way the sampling is performed may not allow a fine, stratified analysis by individual characteristics, which is of particular interest when studying transit safety.

Moreover, safety surveys are often performed by the individual transportation authorities in large cities and may not be comparable across countries. While in London, Transportation for London (TfL) regularly performs surveys to check attitudes to safety and security (by different transportation modes, and questions include unwanted sexual behaviour and sexual violence), in Stockholm, the municipal safety survey questions about transit safety do not consider sexual harassment and/or other sexual crimes, and they are also general for the whole subway system (Ceccato 2013). As the article by Lea and colleagues show, new technologies (e.g. digital platform for reporting and analysing cases of violence) can be an alternative to using crowdsourced data. Although the use of these new technologies is still in its infancy, the authors suggest that it has shown promising results in addressing sexual harassment and assault on public transport. Future research should assess on the variety of ways in which technology can be used by transport agencies and by the general public to prevent, record and report sexual offences on public transport (Gekoski et al. 2015, pp. 40-41, 62).

A limitation of this special issue is that it does not deal with other genders and transit environments. It has been a conscious choice to concentrate this special issue on women only since we believe the topic per se is complex and not yet well understood in the context of transit environments. A special issue on gender and transit safety would have taken the discussions beyond women's safety and especially beyond the 'opposite halves': women and men. For instance, issues of masculinity and fear could be an interesting topic for further exploration. Moreover, it is important to consider victimisation against other gender groups (such as the LGBTQ community) who are potentially a target of sexual violence. We are aware that in many parts of the world, there have been numerous examples of gay and transgendered persons being targets of harassment and violence in transit (e.g. Gekoski et al. 2015; UOL 2014). This fact calls for a better understanding of those cultural, psychological and societal contexts that are linked to females and males, but also to those gender identities that go beyond this binary model.

This special issue has combined empirical research drawing from case studies from Brazil, France, India, Italy, the UK and the USA, which is a major 
achievement. However, it would be strengthened from further examples from societies where gender roles are predefined by other societal norms than those found in, e.g. North America and Western Europe. In countries like Japan, for example, young women are frequently subject to unwanted sexual contact in public transit, as they are elsewhere in other countries (Peters 2013). However, in some countries with extreme levels of gender inequality, transit agencies have decided to improve women's safety by segregating women from men and implementing women-only transportation (for a review of examples, see Gekoski et al. 2015). Some suggest that whereas 'women-only' solutions may be appropriate, 'they remain problematic in that they perpetuate differences rather than comprehensively addressing the deep rooted gender biases inherent in current transport planning and policy-making' (Peters 2013, p. 35). Others claim that there have been examples in which womenonly transportation creates a platform to trigger change to the root causes of violence against women in public transportation (Dunckel-Graglia 2013; Gekoski et al. 2015). Despite the controversy, little is known about the overall long-term effects of these 'women-only' solutions across countries.

Another area that requires further research is women's safety in Muslim societies, especially in those in which the pardah (the practice of gendersegregating access to public areas) is a key factor determining women's public life. In Bangladesh, for instance, women heavily depend on rickshaws for door-to-door travel (Peters 2013). Recent studies in Iran and Pakistan (Arjmand 2017; Iqbal 2016) on the so-called 'women's only parks' illustrate the need for a better understanding of women's safety in these countries, not least while in transit to and from these parks and other public places.

\section{Tackling problems of women's transit safety: main recommendations}

The international literature shows that there is no single initiative that comprehensively deals with unwanted sexual behaviour and sexual crimes in transit environments. Some ways to tackle the problem have to change the way boys and girls are educated, i.e. long-term changes of the societal norms that impose different conditions for men and women. The changes are important but lay far beyond the scope of this special issue. An additional route to take is to change the criminogenic conditions of places; thus, instead, a multifaceted approach, with complementary initiatives, is the most effective means. After compiling a vast number of studies, Gekoski et al. (2015, p. 53) suggest that these initiatives could include: (a) increased surveillance in the form of extra transport staffing and police (both uniformed and plain clothes), as well as technological surveillance such as CCTV; (b) crime prevention through environmental design (CPTED) measures such as increased visibility, lighting, alarms, phones and good maintenance of transport facilities; (c) alternative means of reporting such as the use of hotlines, texting and phone apps; (d) awareness campaigns through advertising, grassroots actions and online platforms; and (e) use of new technologies such as smartphone apps to report incidents, track passengers, record experiences and create maps of offending hotpots. 
Table 1 Tackling problems of women's transit safety: summary of recommendations

\begin{tabular}{|c|c|c|c|c|c|}
\hline & $\begin{array}{l}\text { (1) Improving } \\
\text { physical } \\
\text { environment and } \\
\text { technological } \\
\text { solutions }\end{array}$ & $\begin{array}{l}\text { (2) Strengthening } \\
\text { social control and } \\
\text { management }\end{array}$ & $\begin{array}{l}\text { (3) Creating } \\
\text { campaigns } \\
\text { and policy } \\
\text { frameworks }\end{array}$ & $\begin{array}{l}\text { (4) Reporting } \\
\text { and } \\
\text { improving } \\
\text { knowledge } \\
\text { basis }\end{array}$ & $\begin{array}{l}\text { (5) Promoting } \\
\text { transit safety } \\
\text { as individual } \\
\text { right }\end{array}$ \\
\hline $\begin{array}{l}\text { Natarajan } \\
\text { et al. }\end{array}$ & $\bullet$ & & $\bullet$ & $\bullet$ & \\
\hline $\begin{array}{l}\text { Jubainville } \\
\text { and Vanier }\end{array}$ & & - & $\bullet$ & $\bullet$ & \\
\hline $\begin{array}{l}\text { Ball and } \\
\text { Wesson }\end{array}$ & & & - & - & \\
\hline $\begin{array}{l}\text { Ceccato and } \\
\text { Paz }\end{array}$ & & ○ & $\bullet$ & $\bullet$ & $\bullet$ \\
\hline Lea et al. & & $\bullet$ & - & & \\
\hline Tripathi et al. & 0 & & ○ & $\bullet$ & $\bullet$ \\
\hline $\begin{array}{l}\text { Vanier and } \\
\text { Jubainville }\end{array}$ & $\bullet$ & $\bullet$ & $\bullet$ & & \\
\hline Iudici et al. & & & & • & - \\
\hline
\end{tabular}

We have also summarised a set of recommendations, based on the articles belonging to this special issue, to tackle unwanted sexual behaviour and sexual crime in transit environments (Table 1). Some may refer to a specific crime type and/or situational condition by transport nodes (bus stops, stations), or a particular group of women; others are individual and joined lines of action for public transport authorities, public organisations and private providers as well as law enforcement practitioners. They are grouped in five groups: (1) Improving physical environment and technological solutions; (2) Strengthening social control and management; (3) Creating campaigns and policy frameworks; (4) Reporting and improving knowledge basis; and (5) Promoting transit safety as individual right. Table 1 indicates that most articles suggest the need of creating campaigns of awareness of the problem, changing policy frameworks, creating strategies to improve reporting as well as improving knowledge basis on women's transit safety.

(1) Improving physical environment and technological solutions

- installing CCTV and surveillance, emergency phones and underground Wifi (Natarajan et al.)

- designing harassment-free, safe environments, design of streets and pedestrian walkways (Natarajan et al.)

- lighting and guardianship could be improved in transit environment at these specific hours to make up for the poorly lit areas (Vanier and Jubainville)

- transport agencies could consider adjusting the size of carriages according to passenger density for peak and off-peak hours (Vanier and Jubainville)

- instating prevention measures to combat sexual harassment and/or sexual violence in the metro (CCTV, guards) which take into account that these 
offences show distinct temporal peaks that correspond to people's daily routine activities (Ceccato and Paz)

- using ICT technologies and social media to faster inform passengers and report problems (Ceccato and Paz)

- CCTV cameras or additional security personnel will have a significant impact on the problem (Tripathi et al.)

(2) Strengthening social control and management

- increasing the number of safety agents to improve perceived safety in empty carriages (Vanier and Jubainville)

- increasing guardianship at specific locations or specific times where maximum harassment takes place (Tripathi et al.)

- increasing human guardianship at particular times of the day/night (Jubainville and Vanier)

- establishing joint safety initiatives directed at women's safety together with police stations, including women's police stations, where they exist (Ceccato and Paz)

- encouraging drivers and other passengers to intervene when a woman or girl seeks help (Lea et al.)

(3) Creating campaigns and policy frameworks

- public transport authorities could launch awareness campaigns against incivilities (Vanier and Jubainville)

- providing emergency call numbers and easy access to reporting (Natarajan et al.)

- sharing strategies and getting institutions, organisations and the public at large to work together to reduce the incidence of violence against women (especially women with disabilities) on public transport (Iudici et al.)

- creating special programs focused on particular problem areas-central stations, for example, at particular times (Ceccato and Paz)

- implementing specific policies to give these vulnerable users more travel choices, or make them safer in the transit environment (Jubainville and Vanier)

- providing assurance to women and girls who are faced with sexual harassment or assault while riding on public transport (or witnesses of such) that it is 'acceptable to make a scene' (Lea et al.)

- ensuring that fellow passengers can be a valuable source of additional surveillance and reporting (Ball and Wesson)

- making sure that transport providers create victim support systems to increase women's willingness to report when something happens (Ceccato and Paz)

- establishing clear government guidelines for allocating specific areas of responsibility for ensuring passenger safety to various public and private 
agencies involved in the provision, maintenance and security of various public transports (Tripathi et al.)

- the guidelines should also lay down the framework whereby responsible agencies are charged with identifying vulnerabilities in the public transport system that facilitate sexual harassment, and putting in appropriate preventive measures (Tripathi et al.)

- the framework should specify mechanisms to ensure coordination and information sharing between the police, transport providers and interested NGOs in the area of security provision (Tripathi et al.)

- avoiding one-size-fits-all solutions to the problem of women's avoidance behaviour in public transport for safety reasons. Instead tailor solutions to women's specific needs (Jubainville and Vanier)

(4) Reporting and improving knowledge basis

- carrying out extensive victimisation surveys to assist the efforts of public and law enforcement authorities in concentrating their efforts at targeting scarce resources most effectively (Tripathi et al.)

- widening the focus of reporting unwanted sexual behaviours (Ball and Wesson)

- investigating women's avoidance behaviour in public transport to identify and address the needs of these users (Jubainville and Vanier)

- improving data quality, e.g. when reports are made, more information needs to be obtained on the conditions surrounding the crime (Iudici et al.)

- The reluctance of 'bystanders' to act is not well understood. Further consideration to the bystander perspective is needed. Such information would be valuable to help develop further initiatives and may further contribute to 'what works' in the reduction in unwanted sexual behaviours (Ball and Wesson)

- improving understanding of the barriers to tackling problems of women's safety while in transit using 'a whole journey approach' and incorporating women's voices and views into transport services policies (Ceccato and Paz)

(5) Promoting transit safety as individual right

- considering women's safety in transit as an individual right, by taking differences in women's needs into account when providing transportation services (Ceccato and Paz, Iudici et al.)

- ensuring that transport providers fulfil minimum standards of service provision via contractual obligations (Tripathi et al.)

- the department for transport (or its equivalent) taking responsibility for liaising with law enforcement to ensure women is provided with adequate 
protection-this includes measures like background checks on transport staff in sensitive positions (Tripathi et al.)

- creating additional avenues whereby women can go and get support other than reporting to the police, such as NGO's, women's group through women's active action and participation (Ceccato and Paz)

- changing education of those who plan, build and renew city environments. The relationship between women's fear of crime, victimisation and public space should be taught to students of architecture, sensitising future architects to gender-based actual threats to personal security (Ball and Wesson).

\section{Conclusion}

Safety and security are crucial issues which disproportionately affect women while in transit (Loukaitou-Sideris 2016; Peters 2013; UN Women 2017). Cases of sexual harassment and other types of sexual crimes against women in transit environments are underreported worldwide, as suggested in the articles presented in this special issue, and this underreporting adds to the difficulty in dealing with the problem. New technologies of data collection (websites, mobile phones, apps, crowdsourced platforms) and analysis (visualisation, data mining, spatial analysis, video analysis) can create opportunities (as suggested in the articles by Lea and colleagues and Ball and Wesson) to tackle sexual harassment and offences in public spaces, including in transit environments. As suggested by Gekoski et al. (2015), further research is needed to identify the types of technologies that are being or could be used and their effectiveness.

In many countries, issues of women's safety in transit environments touch upon more fundamental challenges in the delivery and provision of public transportation services. Overcrowded public transportation systems affect women in particular, but it is a general problem that affects all users. Access to safe and reliable transportation is an individual right, which is not satisfied in many cities (particularly those in the Global South). Improvements in women's transit safety are undermined without overall improvements in public transportation. Programs that are directed to increase awareness of the problem and increase reporting practices (as the ones illustrated in this special issue) are important but they have limited effect if not linked to structural changes in the delivery of public transportation services. As the articles have illustrated, current initiatives to prevent sexual harassment and other unwanted sexual behaviour have so far been limited to attempting to prevent these incidents from occurring (instalment of CCTV, awareness campaigns), and if they do happen, that they are properly reported (guards and sms-campaigns). However, post-incident support at particular spots (stations, carriages) is still lacking from the examples illustrated in this special issue. Women need to know they can take legal actions against service delivery companies in transportation in case they are harassed or suffered any other type of victimisation while in transit. A potential way forward is that transportation 
operators seek partners among non-profit organisations, NGOs and local groups to deal with women's transit safety needs (Loukaitou-Sideris 2016). A type of postincident support platform (to deal with it emotionally and legally) supported by a constellation of actors would be desirable so more women dare to come forward when something happens. The legitimacy of current programs is undermined by the fact that the support that women's receives stops at reporting the case to the authorities. To engage women in the process of change is essential and this require some long term investments in programs supporting women to make authorities responsible for their safety.

On long term, there is a need to rethink the education of those who plan, build and renew city environments, such as architects, engineers and urban planners. Courses on principles of Crime Prevention Through Environment Design (Ekblom 2014; Armitage 2013) can be helpful but may not be enough (Keddy 2015). As suggested in this special issue, the relationship between women's fear of crime and victimisation in public space should be taught to students, sensitising future professionals to gender-based actual threats to personal security and perceived safety.

If one takes the issue of the physical environment, the design of transit vehicles, stops and systems, as suggested by Loukaitou-Sideris (2016, p. 559), can contribute to comfort and perceived safety for all riders, particularly women. She illustrates by suggesting 'the placement of bus stops at settings that facilitate natural surveillance by bystanders, as well as good lighting, make the wait for the bus less stressful'. In this context, some of the recommendations put forward in this special issue can also be helpful as a starting point.

In this special issue, articles took distance from radical solutions for women's transit safety problems, such as women-only trains, buses and taxis. First, because there is an underlying assumption that these solutions may not be appropriate for countries where gender inequalities do not preclude into extreme, unsafe transit conditions. Second, although women-only transport may be an effective means of reducing unwanted sexual behaviour on public transport in some countries, they are, as suggested by Gekoski et al. (2015), 'short-term fixes' to the problem. Yet, this does not mean that gender-neutral safety policies are likely sufficient to tackle women's needs (Ceccato 2013; Gekoski et al. 2015; Loukaitou-Sideris 2016). Peters (2013) suggests; 'transit agencies may have a general interest in providing adequate service to all customers, but unless a specific effort is made to ask both men and women what they need and want and how services can be improved, sub-optimal solutions persist'. Thus, a better understanding of the societal, economic and institutional barriers that hamper the incorporation of women's voices and views into transport service policies is necessary.

Overall, this special issue has made an effort to provide examples of studies on women's transit safety from an international perspective, often using small-scale studies and a variety of exploratory approaches. This task is far from complete but as the examples in this special issue have illustrated, steps forward have been taken. 


\section{References}

Armitage, R. 2013. Crime prevention through housing design: Policy and practice. Basingstoke: Palgrave MacMillan.

Arjmand, R. 2017. Public urban space, gender and segregation: Women-only urban parks in Iran. London: Taylor \& Francis.

Ceccato, V. 2013. Moving safely: Crime and perceived safety in Stockholm's subway stations. Lexington: Lanham.

Ceccato, V., D.J. Wiebe, B. Eshraghi, and K. Vrotsou. 2017. Women's Mobility and the Situational Conditions of Rape: Cases Reported to Hospitals. doi:10.1177/0886260517699950.

Datafolha. 2014. Termômetro Paulistano - Assédio Sexual Contra as Mulheres. www.datafolha.com.br. Accessed 19 May 2017.

Dunckel-Graglia, A. 2013. Women-only transportation: How "pink" public transportation changes public perception of women's mobility. Journal of Public Transportation 16(2): 85-105.

Ekblom, P. 2014. Design and security. In The handbook of security, ed. M. Gill, 133-158. Basingstoke: Palgrave Macmillan.

Gekoski, A., M. Jacqueline, M.H. Gray, S.E. Horvath, E. Aliye, and J. Adler. 2015. 'What works' in reducing sexual harassment and sexual offences on public transport nationally and internationally: A rapid evidence assessment. http://www.mdx.ac.uk/_data/assets/pdf_file/0019/155800/WhatWorks-in-Reducing-Sexual-Harassment-and-Sexual-Offences-on-Public-Transport-Nationally-andInternationally.pdf. Accessed 19 May 2017.

Harris, C., L. Jackson, A. Piekut, and G. Valentine. 2017. Attitudes towards the 'stranger': Negotiating encounters with difference in the UK and Poland. Social and Cultural Geography 18(1): 16-33.

Hewitt, A., and E. Beauregard. 2014. Sexual crime and place: The impact of the environmental context on sexual assault outcomes. Journal of Criminal Justice 42(5): 375-383.

Iqbal, A. 2016. Women-only parks (WOPs): Assessment of perceived safety in Karachi, Pakistan. Paper presented at the American Society of Criminology, ASC, New Orleans. https://convention2. allacademic.com/one/asc/asc16/. Accessed 19 May 2017.

Keddy, K. 2015. "Safety is just a thing men take for granted": Teaching a spatial vocabulary of equality to architecture students. Atlantis: Critical Studies in Gender, Culture \& Social Justice 37(1): 39-53.

Loukaitou-Sideris, A. 2016. A gendered view of mobility and transport: Next steps and future directions. Town Planning Review 87(5): 547-565.

Madan, M., and M. Nalla. 2015. Sexual harassment in public spaces: Examining gender differences in perceived seriousness and victimization. International Criminal Justice Review 26(2): 80-97.

Natarajan, M. 2016. Rapid assessment of "eve teasing" (sexual harassment) of young women during the commute to college in India. Crime Science 5(1): 1-11.

Peters, D. 2013. Gender and sustainable urban mobility. https://unhabitat.org/wp-ontent/uploads/2013/ 06/GRHS.2013.Thematic.Gender.pdf. Accessed 19 May 2017.

Smith, M.J. 2008. Addressing the security needs of women passengers on public transport. Security journal 21(1): 117-133.

Sokoloff, N.J., and I. Dupont. 2005. Domestic violence at the intersections of race, class, and gender: challenges and contributions to understanding violence against marginalized women in diverse communities. Violence against Women 11: 38-64.

Suarez, E., and T.M. Gadalla. 2010. Stop blaming the victim: A meta-analysis on rape myths. Journal of Interpersonal Violence 25(11): 2010-2035.

Sweet, E.L., and S.O. Escalante. 2010. Planning responds to gender violence: Evidence from Spain, Mexico and the United States. Urban Studies 47(10): 2129-2147.

UN Women. 2017. Creating safe public spaces. Safe cities global initiatives. www.unwomen.org. Accessed 19 May 2017.

UOL. 2014. Casal Homossexual é Espancado por 15 Homens no Metrô de São Paulo. http://noticias.uol. com.br/cotidiano/ultimas-noticias/2014/11/12/casal-homossexual-e-espancado-por-15-homens-nometro-de-sao-paulo.htm?cmpid=copiaecola. Accessed 19 May 2017.

Valentine, G. 1990. Women's fear and the design of public space. Built Environment 16(4): $288-303$.

Valentine, G. 1992. Images of danger: Women's sources of information about the spatial distribution of male violence. Area 24(1): 22-29. 